Research Article

\title{
Theoretical and Experimental Performance Analysis of a Novel Domestic Biogas Burner
}

\author{
Lucia M. Petro $\mathbb{D D}^{1,2}$ Revocatus Machunda $\mathbb{D}^{1},{ }^{1}$ Siza Tumbo $\mathbb{D}^{3},{ }^{3}$ and Thomas Kivevele $\mathbb{D}^{1}$ \\ ${ }^{1}$ School of Materials, Energy, Water and Environmental Sciences (MEWES), Nelson Mandela African Institution of Science and \\ Technology (NM-AIST), P. O. Box 447, Arusha, Tanzania \\ ${ }^{2}$ Department of Mechanical Engineering, Arusha Technical College, P. O. Box 296, Arusha, Tanzania \\ ${ }^{3}$ Ministry of Agriculture, P. O. Box 2182, Dodoma, Tanzania
}

Correspondence should be addressed to Lucia M. Petro; petrol@nm-aist.ac.tz

Received 17 June 2020; Revised 6 August 2020; Accepted 27 August 2020; Published 16 September 2020

Academic Editor: Mohammad Khan

Copyright $\odot 2020$ Lucia M. Petro et al. This is an open access article distributed under the Creative Commons Attribution License, which permits unrestricted use, distribution, and reproduction in any medium, provided the original work is properly cited.

\begin{abstract}
The inefficient indoor burning of fuelwood on traditional cookstoves generates pollutants, primarily carbon monoxide and many other human health-damaging emissions. It is from this risk that it is necessary to have an immediate shift to alternative cleaner fuel sources. Biogas, which is among the biofuels from biomass, is one of the resources that play a considerable part in a more diverse and sustainable global energy mix. For domestic purposes in rural areas of Tanzania, biogas provides a better option that can supplement the use of fossil fuels such as wood, charcoal, and kerosene, which is nonrenewable. However, the low efficiency experienced in the locally made biogas burners hinders the large-scale use of biogas among the population in the country. With the locally made burners, the users of biogas for the domestic application face problems including heat loss and high gas consumption which affects the whole cooking process. It is against this backdrop that the current study objectives incline on designing and improving the efficiency of the locally manufactured burners to achieve the uniform flow of fuel in the mixing chamber, which will result to the consistent heat distribution around the cooking pot. The optimization of the burner was done by using computational fluid dynamics (CFD) through varying the number of flame portholes and air holes as well as the size of the jet before fabrication. The increased efficiency of the burner has also contributed by the addition of the fuel distributor. The results showed that the optimum hole diameter of the jet was $2.5 \mathrm{~mm}$ and that of the manifold was $100 \mathrm{~mm}$. The currently developed biogas burner was tested and compared with the other two locally made burners. The water boiling test (WBT) on these three burners showed that the developed burner has a thermal efficiency of $67.01 \%$ against $54.61 \%$ and $58.82 \%$ of the Centre for Agricultural Mechanization and Rural Technology (CARMATEC) and Simgas, respectively. Additionally, the fuel consumption of the developed burner was $736 \mathrm{~g} / \mathrm{L}$ as compared to $920 \mathrm{~g} / \mathrm{L}$ for CARMARTEC and $833 \mathrm{~g} / \mathrm{L}$ for that of Simgas. The developed burner and its corresponding cookstove are both environmentally friendly and economical for household utilization in Tanzania and other developing countries.
\end{abstract}

\section{Introduction}

Energy is a crucial requirement for the development of a country. Around $80 \%$ of the population in Tanzania have no access to power, particularly electricity. They, subsequently, strongly depend on conventional energy sources such as charcoal and firewood for cooking, lighting, and other applications as an alternative [1]. Approximately $90 \%$ of the energy needs of the rural people in Tanzania come from biomass $[1,2]$. Environmental degradation due to deforestation for firewood and charcoal has increased drastically, leading to soil erosion [3]. Heating and cooking exercises within the family units are generally done by the utilization of firewood and charcoal, which causes indoor air pollution leading to infections that, in most cases, affect women and children [1]. The inefficient burning of biomass on conventional cookstoves produces emissions, mainly carbon monoxide and other human health-damaging pollutants such as nitrogen oxides, benzene, butadiene, formaldehyde, and polyaromatic hydrocarbons. Biogas is a renewable 
energy resource and an alternative biomass option that can counteract these effects [4] and is obtained from inexpensive, readily available material wastes in rural areas, such as animal wastes and crop wastes [5]. In Tanzania, around 21 tons of cow dung are produced each year and can be gasified to create heat energy [6]. Biogas is considered one of the greatest substitute fuel that can supplement the utilization of solid biomass and fossil fuel for household applications, especially in developing countries, Tanzania inclusive [7]. It is environmentally, and it eliminates workload on women livelihood, hence improves lives [8]. The successful use of biogas reduces the country's dependence on fossil fuels [9].

Few studies have specifically investigated the thermal performance of locally made biogas burners theoretically and experimentally. Mulugeta et al. [29] did research on biogas injera baking burner with a manifold external diameter of $170 \mathrm{~mm}$. The experiment and analysis results demonstrated that the burner was small, and therefore, insufficient for baking the injera pieces of breads. This was caused by the nonuniform distribution of heat along with the baking pan.

Decker [10] conducted research on burner flame portholes. The burner consisted of rectangular flame portholes which caused the friction during air-fuel mixture flow, hence reducing the flame stability. Orhorohoro et al. [11] designed an improved biogas fuel stove because the existed burner had low efficiency. The study focused on the gap between flame portholes, mixing tube length, flame port diameter, and distance between cooking pot and stove burner. After the analysis and improvement, the maximum efficiency obtained was 63.87\%. Sukhwani et al. [12] designed and conducted a performance evaluation of an improved biogas stove. In the analysis, the variation of burner flame port diameter was done as well as preheating of the biogas to increase its efficiency. The results showed an increased performance efficiency of $42.99 \%$.

The existing burners consist of flame ports located on their outer circumference which allow only for cooking and cannot be used for preheating. This arrangement increases the costs for users because even preheating consumes more fuel. Therefore, domestic users face challenges including heat loss, low heating value, and high gas consumption which affect the whole cooking process. Other factors which cause low efficiency are flame speed (velocity), manifold size, and pot to burner distance [13].

The information provided in this paper is useful for generating knowledge and findings on improving the performance of locally made burners. Therefore, the main aim of this study is to optimize the performance of a novel biogas burner made using local and low-cost materials.

\section{Materials and Methods}

2.1. Analytical Design of Biogas Burner. The technique and analytical design of the burner involved the determination of various important factors such as jet diameter, throat diameter, area of the burner port, number of ports, and area of the jet $[14,15]$.
2.1.1. Determining Output Power and Biogas Flow Rate. The strategy adopted in this study comprised the $3 \mathrm{D}$ geometrical design of a burner, numerical design analysis using CFD, analytical design procedures, and manufacture of a prototype. The analytical design adopted for biogas burner [16].

The output power of the stove $(\mathrm{kW})$ was calculated using equation (1) [17]:

$$
P=5.2(V / t)
$$

where $V$ is the volume of water in liters and $t$ is the time consumed to boil such amount of water.

The gas flow rate, $Q$, can be determined by equation (2) [17]:

$$
Q=0.45(P)
$$

where $Q$ biogas is the flow rate in $\mathrm{m}^{3} / \mathrm{h}$ and $P$ is the output power in $\mathrm{kW}$.

2.1.2. Jet Diameter, $d_{j}$. The jet diameter, $d_{j}$, was calculated by using equation (3).

$$
\boldsymbol{d}_{\boldsymbol{j}}=\sqrt{\frac{Q_{\text {biogas }}}{0.0361 \times C_{d}}} \times \sqrt[4]{\frac{s}{p}},
$$

where $C_{d}$ is the coefficient of discharge for injector jet, $p$ is the gas pressure before injector jet, and $s$ is the specific gravity of the gas. (4).

The area of injector jet $\left(A_{j}\right)$ was calculated using equation

$$
A_{j}=\frac{\pi \times\left(d_{j}\right)^{2}}{4} .
$$

The biogas velocity in the injector jet, $V j$, was determined according to equation (5).

$$
\boldsymbol{V}_{\text {gas }}=\frac{Q_{\text {biogas }}}{A_{j}} .
$$

2.1.3. Determination of Throat Diameter, $d_{t}$. The throat diameter was determined using Prig's formula, shown in equation (6).

$$
d_{t}=\left[\left(\frac{r}{\sqrt{s}}+1\right) d_{j}\right],
$$

where $r$ is entrainment ratio and $s$ is the specific gravity of the gas.

According to Fulford [15], it is recommended to double the throat diameter for best design.

The exact size depends on the standard pipe sizes available.

2.1.4. Determination of Burner Port Design. As suggested by Fulford [15], the stoichiometric flame speed of biogas is $0.25 \mathrm{~m} / \mathrm{s}$. 
The blending supply velocity, $v_{p}$, is given by Fulford [15]:

$$
V_{p}=\frac{Q_{m}}{A_{p}} \ll 0.25 \mathrm{~m} / \mathrm{s} .
$$

The burner port area was solved as follows:

$$
A_{p}>\frac{Q_{m}}{V_{p}} \gg 0.0025 \mathrm{~m}^{2}
$$

From the design calculations, the centre flame port distance from one hole to another is $3 \mathrm{~mm}$ to avoid the flame lift. Then, the number of flame portholes was calculated according to equation (9)

$$
n_{p}=\frac{4 A_{p}}{\pi d_{p}^{2}}
$$

where $n_{p}$ is the number of holes and $d_{p}$ is the diameter of each hole in meters.

2.2. Burner Drawings and Geometry Modelling. The parameters obtained from the analytical design were used to generate $3 \mathrm{D}$ drawings of the burner using the SOLID WORKS software, as shown in Figure 1.

The 3D geometry of the model has then imported in ANSYS Workbench for further analysis, as shown in Figure 2.

2.2.1. CFD Simulation of the Burner. The CFD study is based on creating the simulation of biogas combustion of the optimized burner. The simulation was performed by applying the ANSYS 16.0 software, and the modeller was used to model the burner while the meshing was done by ANSYS (ICEMCFD), and the solution was computed by the use of the fluent (postprocessor). It is important to mention that CFD can design and simulate a model without physically constructing the model. Numerical modelling technique including but not limited to CFD methods has gained fame in academic and industrial sectors because of the availability of efficient computer systems. It is possible to optimize the system design operation and understand physiochemical properties inside the model using CFD simulations, which can consequently reduce the number of experiments required for characterization of the system. Simulations produce spatial and temporal profiles of different system variables that are either impossible to measure or are accessible only by expensive experiments [18].

Figure 3 shows the 3D geometry based on the actual dimensions. Each measurement was checked on the plan with corresponding input measurements which can be changed. In this way, each measurement is simple and rapidly modified, and the whole construction can be modified and redrawn, and advanced steps like mesh creation or design optimization are conceivable in real-time $[19,20]$.

It is required to provide grids or mesh into the geometry, where meshing is an essential part of the CFD process because the method chosen on the meshing stage decides the quality of the mesh. Figure 4 shows the meshing of the developed biogas burner with grids of elements employed
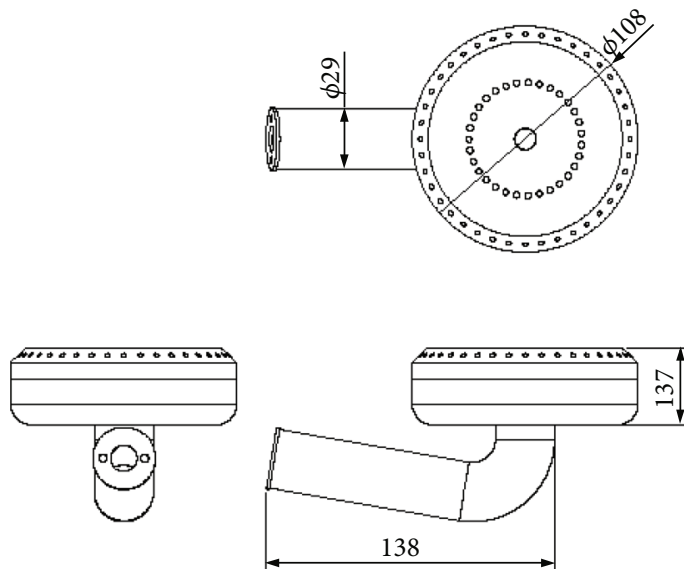

FIgURE 1: 3D geometry of a burner.

to solve liquid flow equations [18]. The grid size has an effect on computational time which directly influences simulation cost as well as the speed of convergence and the accuracy of the solution [21].

To realize sufficient determination of the stream and reduce the time taken by the computer to run the simulation, hexahedral cells are chosen. Also, refined grids reduce the period for calculation, and the convergence is reached more easily [21].

The boundary conditions were indicated according to the profile of the geometry, as shown in Figure 3. The nonpremix combustion with turbulent realizable $\mathrm{K}-\varepsilon$ and the model P1 were used in the simulation of combustion in the newly designed burner. The ANSYS-FLUENT requires input parameters in terms of gas composition concerning $\mathrm{CO}_{2}$ and $\mathrm{CH}_{4}$, which are to be used in the simulation. The transient model was used as the initial setting in 3D geometry with the pressure-based solver. The details of the model parameter settings and model input parameters for the simulation are shown in Tables 1 and 2, respectively.

The nonpremix combustion model was employed, where the initial velocity of air and fuel was considered $5.2 \mathrm{~m} / \mathrm{s}$ and $36.1 \mathrm{~m} / \mathrm{s}$, respectively. Table 3 shows the Probability Density Function (PDF) of boundary conditions for the fuel and oxidant. The biogas contains a mixture of $60 \%$ of $\mathrm{CH}_{4}$ and $40 \%$ of $\mathrm{CO}_{2}$ on a molar basis [22]. As presented in Table 3, the oxidant consists of $21 \%$ and $79 \%$ mixture of oxygen and nitrogen, respectively, similar to the normal combustion air configuration. The temperature of the fuel and oxidant was set at $300 \mathrm{~K}$, and the CFD simulation was performed by varying the geometry dimensions as well as manifold size to achieve the optimum design.

2.3. Fabrication of a Burner. The fabrication of the prototype was done in the workshops of the Centre for Agricultural Mechanization and Rural Technology (CAMARTEC) and at Arusha Technical College (ATC), Arusha, Tanzania. A burner was fabricated basing on the results of CFD analysis. Figure 5 shows the cookstove assembly fabricated to accommodate the burner. The cookstove consists of a burner jet for the fuel flow, a mixing tube comprising of air holes for proper mixing of fuel and air, and a manifold at which the 


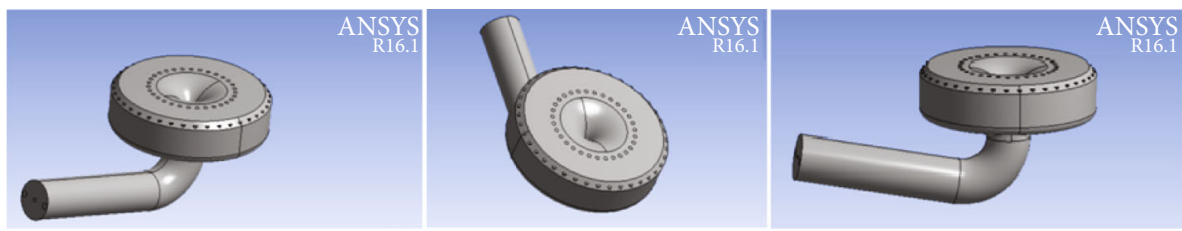

Figure 2: 3D geometry of a burner.

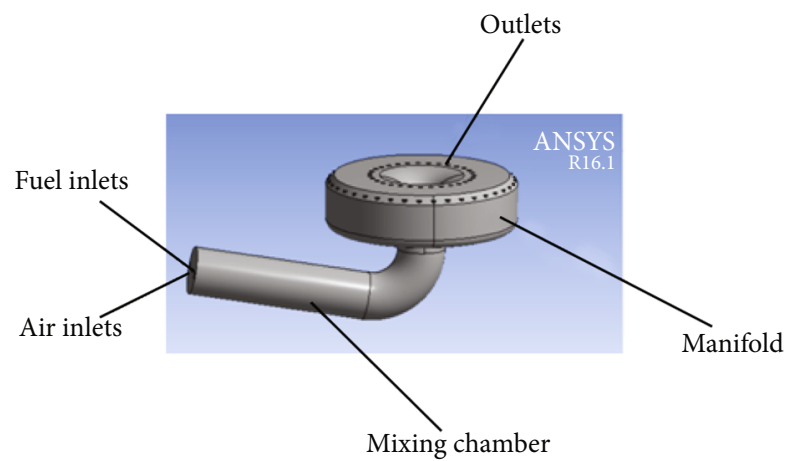

FIgURE 3: Boundary condition of a burner on a 3D model.

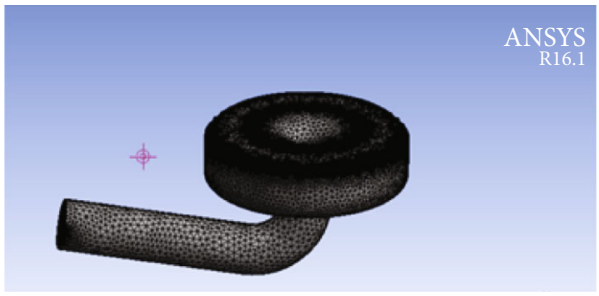

Figure 4: Burner mesh geometry generated using the ANSYS software.

TABLE 1: Settings of the fluent model.

\begin{tabular}{lc}
\hline Model parameters & Status \\
\hline Multiphase & Off \\
Energy & On \\
Viscous & Standard k-e, standard wall fn \\
Radiation & P1 \\
Heat exchanger & Off \\
Species & Nonpremixed combustion \\
Inert & Off \\
NOx & Off \\
SOx & Off \\
Soot & Off \\
Decoupled detailed chemistry & Off \\
Reactor network & Off \\
Reacting channel model & Off \\
Discrete phase & Off \\
Solidification and melting & Off \\
Acoustics & Off \\
Eulerian wall film & Off
\end{tabular}

combustion mixture is distributed to each flame porthole in the burner head. A distributor is provided at the manifold to balance the pressure and ensure equal distribution of airfuel mixture. Additionally, the cookstove has a gas supply pipe which supplies fuel from the source to the control valve. The tripods are fixed on the stove frame to hold the pots as well as to provide the suitable position between the burner top and the pot bottom.

2.4. Evaluation of the Performance of the Burners. The experiments to determine the performance of the burners were carried out in the energy lab at the CAMARTEC in Arusha, Tanzania. The performance of the developed burner was compared with that of the Simgas and CAMARTEC burners. The experiments were designed to simulate real-life cooking processes and were conducted using the water boiling test (WBT).

2.4.1. Theoretical Analysis. The water boiling test (WBT) method was used to assess the thermal efficiency $\left(\eta_{t}\right)$, the firepower (FP), the specific fuel consumption (SC), and the burn rate $\left(r_{b}\right)$ of burner [23]. Several formulae relating to burner performance have been developed. The methods adopted based on the approach done by Berrueta et al. and Ahuja et al. [23, 24].

(1) Thermal efficiency $\left(\eta_{t h}\right)$ was calculated by the ratio of the energy used during heating and vaporizing water to the energy consumed by burning the biogas fuel $[14,25,27]$. Mathematically,

Thermal efficiency, $\eta_{t h}=\frac{\left(\left(C_{\mathrm{pw}} \times M_{w}\right) \times\left(T_{f}-T_{i}\right)\right)+\left(H_{v} \times W_{v}\right)}{C_{v \text { of biogas }} \times V_{\mathrm{bg}}} \times 100$,

where $V_{\mathrm{bg}}$ is the volume of biogas consumed, $\mathrm{m}^{3} / \mathrm{h} ; M_{w}$ is the mass of water boiled, kg; $C_{\mathrm{vbg}}$ is the calorific value of fuel ( biogas) $=22 \mathrm{MJ} / \mathrm{kg} ; C_{\mathrm{pw}}$ is the specific heat capacity of water $=4186 \mathrm{~J} / \mathrm{kg}^{\circ} \mathrm{C} ; T_{f}$ is the boiling temperature of water $=95.23^{\circ} \mathrm{C} ; W_{v}$ is the water evaporated from the pot; $T_{i}$ is the initial temperature of the water, ${ }^{\circ} \mathrm{C}$; and $H_{v}$ is the latent heat of evaporation of water, $2260 \mathrm{~J} / \mathrm{g}$.

(2) Firepower (FP) is the proportion of fuel energy utilization by burner per unit time. It was calculated by equation (11) [23, 27]. Mathematically,

$$
\mathrm{FP}=\frac{V_{\mathrm{bg}} \times \mathrm{LHV}}{60 \times\left(t_{f}-t_{i}\right)}
$$


TABle 2: Model input data of the burner.

\begin{tabular}{lcc}
\hline Parameter & & Value \\
\hline Burner dimensions & $(\mathrm{L} \times \mathrm{H} \times \mathrm{W}) \mathrm{mm}$ & $265 \times 67.5 \times 100$ \\
Species & $\mathrm{CH}_{4}$ & 0.6 \\
& $\mathrm{CO}_{2}$ & 0.4 \\
Air inlets & Velocity $(\mathrm{m} / \mathrm{s})$ & 5.2 \\
& Temperature $(\mathrm{K})$ & 300 \\
Biogas (fuel) & Velocity $(\mathrm{m} / \mathrm{s})$ & 36.01 \\
Operating pressure & Temperature $(\mathrm{K})$ & 300 \\
Gravitational acceleration & $(\mathrm{Pa})$ & 101325 \\
\hline
\end{tabular}

TABLE 3: PDF for boundary conditions.

\begin{tabular}{lcc}
\hline Species & Fuel & Oxidant \\
\hline $\mathrm{CH}_{4}$ & 0.6 & 0 \\
$\mathrm{O}_{2}$ & 0 & 0.21 \\
$\mathrm{~N}_{2}$ & 0 & 0.79 \\
$\mathrm{H}_{2}$ & 0 & 0 \\
$\mathrm{CO}_{2}$ & 0.4 & 0 \\
\hline
\end{tabular}

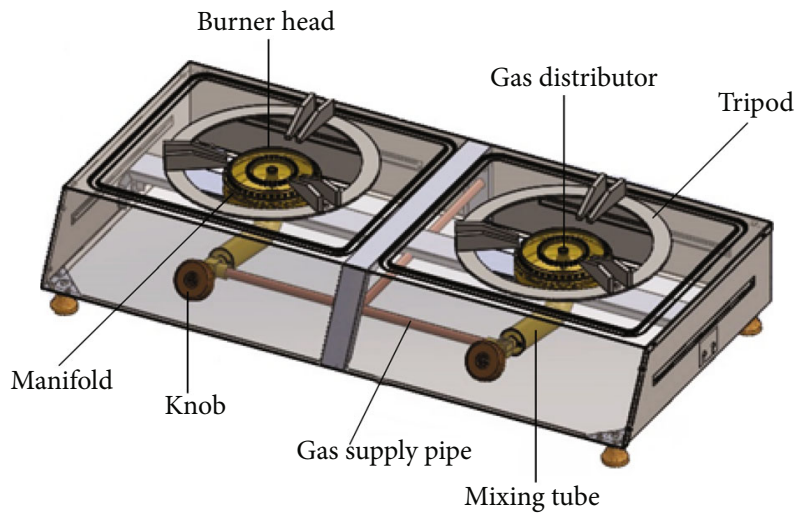

Figure 5: Stove assembly.

where FP is the power of burner in watts, $V_{\mathrm{bg}}$ is the volume of biogas consumed during the stage of the test $\left(\mathrm{m}^{3} / \mathrm{h}\right)$, LHV is the lower heat value of the biogas $(\mathrm{kJ} / \mathrm{kg}), t_{f}$ is the time at the end of the test (min), and $t_{i}$ is the time at the start of the test (min).

(3) Specific fuel consumption (SC) is the proportion of the amount of biogas fuel consumed to the amount of water remaining within the pot at the end of the test. SC was calculated using equation (12) [25]. Mathematically,

$$
\mathrm{SC}=\frac{V_{\mathrm{bg}}}{W_{r}}
$$

where SC is the specific fuel consumption of the burner $(\mathrm{g} / \mathrm{L})$, $V_{\mathrm{bg}}$ is the volume of biogas fuel expended during the phase of the test (g), and $W_{r}$ is the mass of water remaining at the end of the test (g).

(4) Burning rate $\left(r_{b}\right)$ is used to measure the fuel consumption to bring water to boil during the experiment. $r_{\mathrm{b}}$ was calculated using equation (13) [26, 27]. Mathematically,

$$
r_{b}=\frac{v_{\mathrm{bg}}}{\Delta t}
$$

where $V_{\mathrm{bg}}$ is the volume of biogas consumed during the test $\left(\mathrm{m}^{3} / \mathrm{h}\right)$ and $\Delta t$ is the total time taken to conduct the test (min).

2.4.2. The Water Boiling Test (WBT). The water boiling test consisted of three stages. The first stage conducted a test with both cold and hot start conditions in high power start. The second stage was that of lower power (simmering) which simulate slow-boiling tasks [27]. A standard aluminium pot of 3 liters capacity was used in all three experiments. At the high power cold start phase, 2.5 liters of water was boiled at room temperature up to $95^{\circ} \mathrm{C}$ local boiling point. In the high power hot start, the fuel was reset immediately after the cold start phase. The test was repeated to note the difference in performance when the burner is cold and when it is hot. The third stage involved the simmering test, which was done after the high power hot start phase test. This involved measuring the burner capacity to move from high heating to low heating, and each experiment was repeated three times. All three burner stoves were tested at the same time on different days, and average results were recorded [23].

\section{Results and Discussions}

3.1. Computational Fluid Dynamics (CFD) Analysis. Table 4 shows the results of the CFD analysis employed in the study to simulate the fluid flow in the burner. During the simulation of the model, the convergence is reached easily when a set of equations are solved and when the calculations are repeated several times until the flow and the temperature are converged. The default criterion for convergence is that each residual is reduced to a value less than $10^{-3}$ except the energy residual for which the default criterion is $10^{-6}$.

Figure 6 shows the contours of temperature distribution in the burner. It was observed that the temperature distribution along the jet and mixing tube was the same as the room temperature of the air and gas inlets as in the boundary conditions. The temperature was identical throughout the mixing tube and increased to a maximum of $997 \mathrm{~K}$ at the manifold. The temperature in the middle section of the manifold was about $757 \mathrm{~K}$, and it was uniform throughout. Figure 7 is a graph which indicates the distribution of temperature along with the burner. The temperature increased circumferential upwards from the bottom to the upper part of a manifold.

Velocity distribution of air-fuel mixture along the mixing chamber of the burner is shown in Figure 8. The fuel contains 
TABLE 4: The results of the analytical design and CFD input values.

\begin{tabular}{lccc}
\hline s/no & Parts & $\begin{array}{c}\text { Analytical } \\
\text { values }\end{array}$ & $\begin{array}{c}\text { CFD } \\
\text { values }\end{array}$ \\
\hline 1 & Injector diameter $(\mathrm{mm})$ & 2.5 & 2.5 \\
2 & Internal throat diameter $(\mathrm{mm})$ & 18 & 25 \\
3 & Number of burner ports & 71 & 71 \\
4 & Mixing tube length (mm) & 170 & 138 \\
5 & Internal manifold diameter & 100 & 100 \\
6 & (mm) & 2.5 & 2.5 \\
7 & Flame port diameter $(\mathrm{mm})$ & 5.0 & 5.0 \\
\hline
\end{tabular}

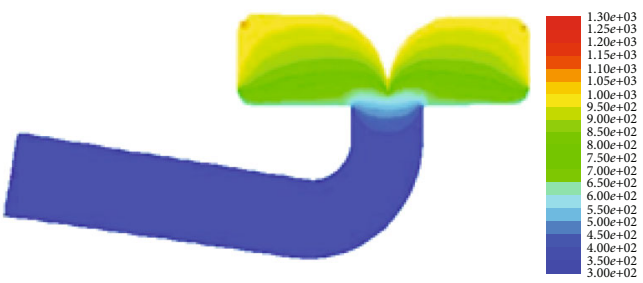

FIgURE 6: Contours of static temperature along the burner.

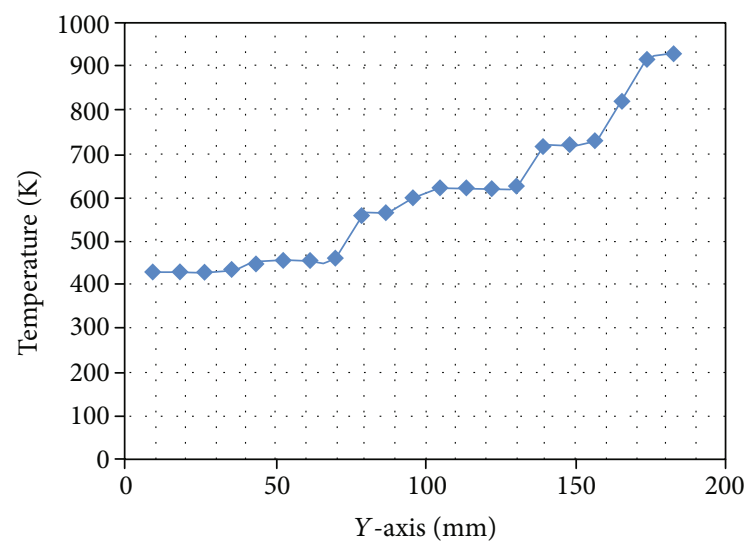

FIgURE 7: Temperature distribution with position along with the burner.

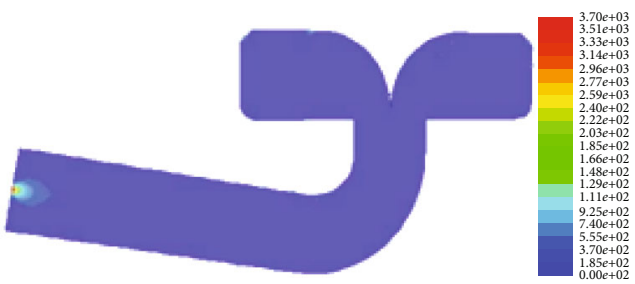

FIGURE 8: Contours of velocity distribution $(\mathrm{m} / \mathrm{s})$.

$\mathrm{CH}_{4}$ and $\mathrm{CO}_{2}$, which play a critical part in the burning process.

The velocity of the air and fuel was higher at the inlets about $5.2 \mathrm{~m} / \mathrm{s}$ and $36.01 \mathrm{~m} / \mathrm{s}$, respectively, and remained uniform at the mixing chamber and along the manifold as

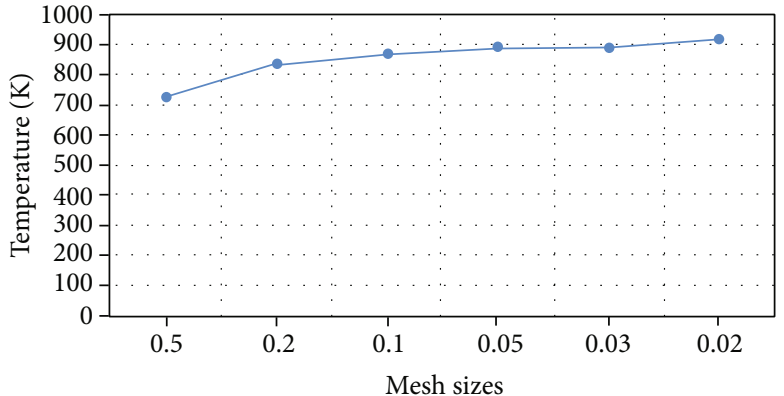

Figure 9: Influence of mesh size on temperature.

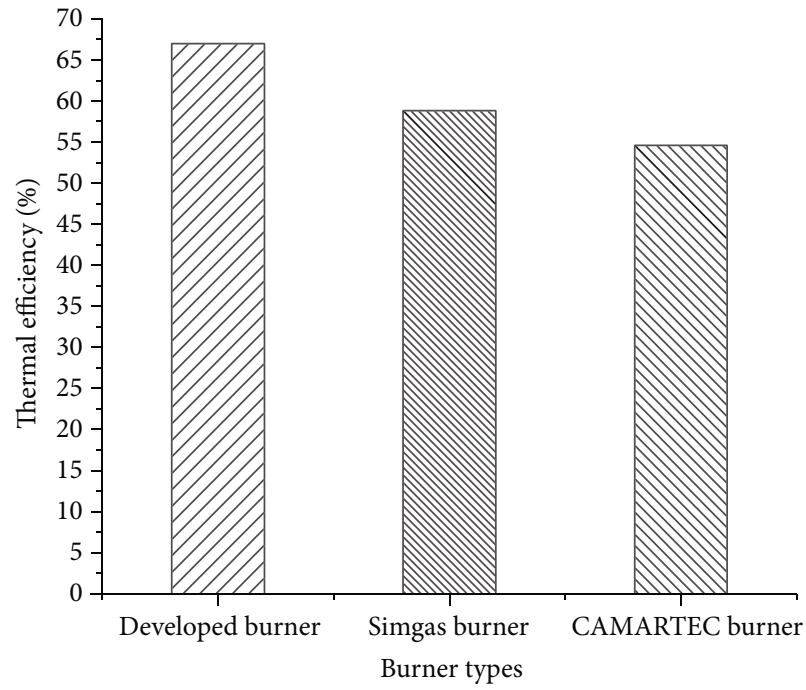

FIgURE 10: Thermal efficiency in the simmering phase of the developed burner and the Simgas and CAMARTEC burners.

shown in Figure 8. These findings are in agreement with other studies done by Decker [27] and Mulugeta et al. [28] and thus indicate that the distribution of velocity is uniform in the manifold. The independent mesh test was performed to verify and show that the results are not dependent on the mesh size. The influence of temperature change basing on the mesh size is shown in Figure 9. During the meshing process, the mesh size was varied from 0.5 to 0.02 , and in those various tests of mesh size, 0.02 is considered appropriate consistently to ensure that temperature was independent of the mesh size.

3.2. Results of Water Boiling Test. The results show that in the HPCS phase, the time taken to boil 2.5 liters of water to the local boiling point was 7 minutes for the developed burner, whereas it took 10 and 11 minutes for the Simgas and CAMARTEC burners, respectively. For the HPHSP, the time taken by the CAMARTEC and Simgas burners to bring 2.5 liters of water to the local boiling point was $10 \mathrm{~min}$, while 7 min taken by the developed burner.

The lower power (simmering) was conducted for 45 minutes, and in a CAMARTEC burner, the water temperature decreased to $78^{\circ} \mathrm{C}$ compared to $89^{\circ} \mathrm{C}$ and $92^{\circ} \mathrm{C}$ of the Simgas and developed burner, respectively, compared to the 


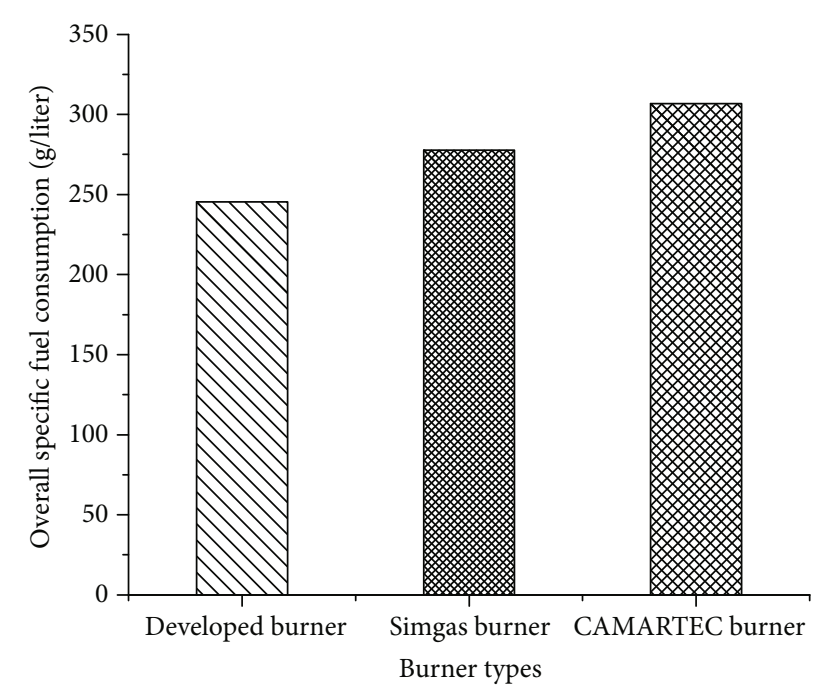

Figure 11: Overall specific fuel consumption over the entire WBT for the three burners.

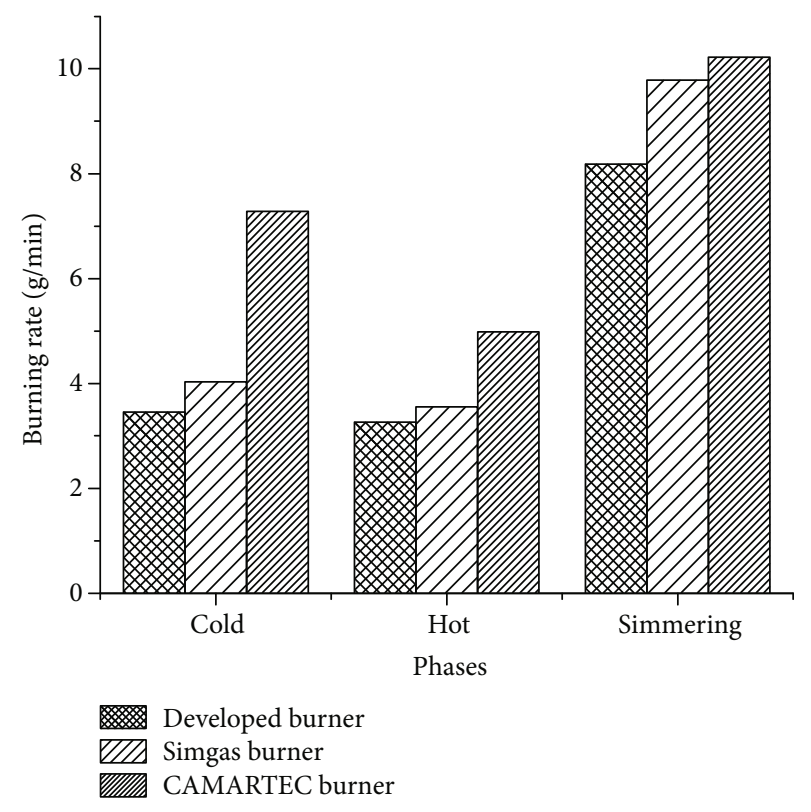

FIgURE 12: Burning rates of the developed burner and the Simgas and CAMARTEC burners.

local boiling point of $95.3^{\circ} \mathrm{C}$. The flame temperature was recorded by infrared thermocouple, and it was about $652^{\circ} \mathrm{C}$ during the peak hour of combustion.

Figure 10 shows the thermal efficiency in the simmering phase of the three burners tested. The developed burner performed the highest efficiency of $67.01 \%$, followed by the Simgas burner with $58.82 \%$, and lastly, the CAMARTEC burner exhibited thermal efficiency of $54.61 \%$. Other researchers such as Orhorohoro et al. [11] did research and find that the optimal cooking efficiency of biogas stove is $63.87 \%$. Another study was conducted by Sukhwani et al. [12] on a designed burner to improve efficiency. The results showed that the performance efficiency was $42.99 \%$. Also, Demissie [14] reported the overall efficiency of a burner stove evalu-

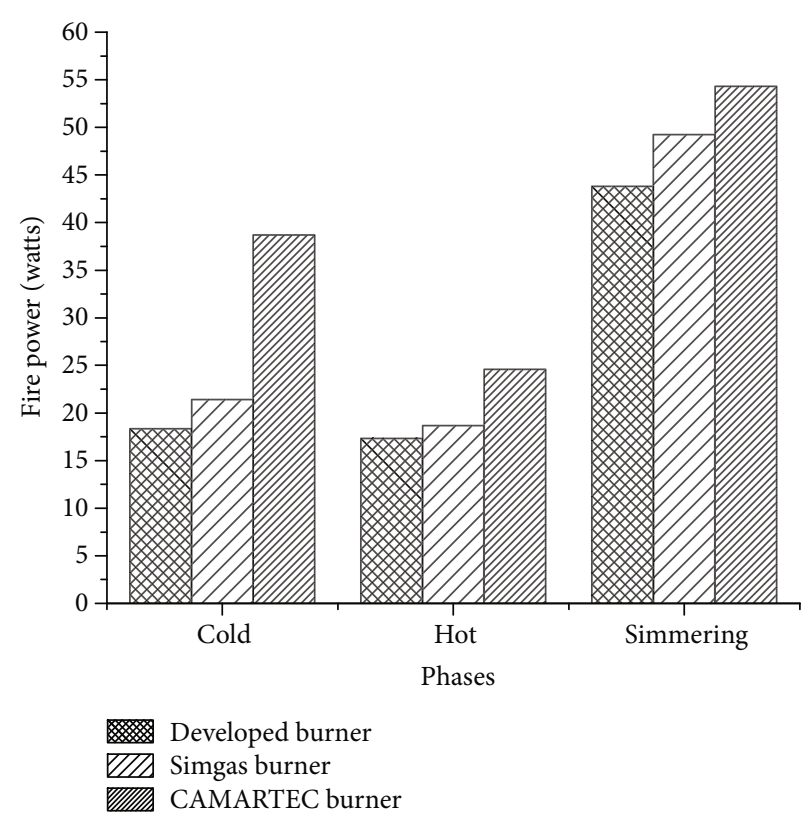

FIGURE 13: Firepower during cold, hot, and simmering phases of the developed burner and the Simgas and CAMARTEC burners.

ated through the water boiling test (WBT) which was found to be $54.8 \%$ and $43.6 \%$ at the higher flame intensity and lower flame intensity, respectively.

The overall specific fuel consumption over the whole WBT for each burner was found to be 245.34, 277.68, and $306.68 \mathrm{~g} / \mathrm{L}$ for the developed burner and the Simgas and CAMARTEC burners, respectively, as shown in Figure 11. The low SFC for developed burner resulted in higher thermal efficiency which is contributed by the addition of a gas distributor in the manifold to balance the pressure and ensure equal distribution of air-fuel mixture in the flame portholes. Furthermore, the small gap between the burner head and the pot bottom was made $30 \mathrm{~mm}$, which keeps the fire closer to the cooking pot most of the time during the tests.

During the high power phase, the developed burner burned fuel at a rate of $3.45 \mathrm{~g} / \mathrm{min}$ and $3.26 \mathrm{~g} / \mathrm{min}$ in the cold and hot phases, while a burning rate of $8.18 \mathrm{~g} / \mathrm{min}$ was achieved in the simmering phase. For the Simgas burner, the average burning rates were $4.03 \mathrm{~g} / \mathrm{min}, 3.55 \mathrm{~g} / \mathrm{min}$, and $9.78 \mathrm{~g} / \mathrm{min}$, respectively, for cold, hot, and simmering phases. While the CAMARTEC burner appeared the highest average burning of $7.28 \mathrm{~g} / \mathrm{min}, 4.98 \mathrm{~g} / \mathrm{min}$, and $10.22 \mathrm{~g} / \mathrm{min}$ in cold, hot, and simmering stage, respectively, as shown in Figure 12. The overall average low burning rate of $4.96 \mathrm{~g} / \mathrm{min}$ managed by the developed burner was attributed to the appropriate design of the burner especially the pot gap that minimized heat losses, and the adjustable primary air hole that ensured well air mixing to reduce flame lift or backfire to the mixing chamber. The overall average high burning rate for the Simgas burner $5.79 \mathrm{~g} / \mathrm{min}$ and $7.49 \mathrm{~g} / \mathrm{min}$ for CAMARTEC burner is due to the big gap between burner head top and bottom pot which consumes a large amount of biogas.

For the cold high power phase, the developed burner and the Simgas and CAMARTEC burners gave firepower of 
$18.33,21.39$, and 38.70 watts, respectively. In hot high power phase, the developed burner and the Simgas and CAMARTEC burners gave firepower of 17.31, 18.6, and 24.56 watts, respectively, whereas in low power, the firepowers for the individual burners were 43.80, 49.23, and 54.32 watts, respectively, as shown in Figure 13. The developed burner displayed better results in terms of firepower because of the modification done on the burner parameters such as the diameter of the injector, throat size, throat diameter, and the height of burner head. Miller-Lionberg [29] reported that increasing the firepower of the burner decreases efficiency.

\section{Conclusion}

The outcomes of this study present perception in the modelling process of the newly designed burner and its performance. The design of the burner consisted of theoretical analysis, numerical design calculations, and computational fluid dynamics (CFD). As per the analytical design, several formulas were used to design the key parts of a burner. The developed burner head consists of 40 portholes located on its outer circumference having $2.5 \mathrm{~mm}$ diameter each and 31 portholes with $2.5 \mathrm{~mm}$ diameter each at its top surface. The manifold of a developed burner has $100 \mathrm{~mm}$ internal and $138 \mathrm{~mm}$ external diameters, respectively. The simulation results show that the maximum flame temperature observed was $997 \mathrm{~K}$ against $925 \mathrm{~K}$ of the experimental measurements.

The water boiling test (WBT) was conducted for the developed burner, and its thermal efficiency performance was $67.01 \%$ against $54.61 \%$ and $58.82 \%$ of the CARMATEC and Simgas burners, respectively. The comparison for the average fuel consumption was also conducted between a developed burner and the abovementioned burners. The test showed that the developed burner fuel consumption was $736 \mathrm{~g} / \mathrm{L}$ compared to $920 \mathrm{~g} / \mathrm{L}$ and $833 \mathrm{~g} / \mathrm{L}$ for the CARMARTEC and Simgas, respectively. The low fuel consumption observed from the developed burner as compared to others was due to the proper distribution of fuel on the cooking pot most of the time during the test.

\section{Data Availability}

The data used to support the findings of this study are available from the corresponding author upon request.

\section{Conflicts of Interest}

The authors declare no conflict of interest.

\section{Acknowledgments}

The authors are grateful for the financial support given by WISE Future. They also recognize the assistance done by CAMARTEC staff and Arusha Technical College staff, especially from the Mechanical Engineering Department for their assistance in this study. This research work was funded by the Water Infrastructure and Sustainability of Energy Futures (WISE- Future scholarship) (Project ID: PI51847).

\section{References}

[1] M. Felix and S. H. Gheewala, "A review of biomass energy dependency in Tanzania," Energy Procedia, vol. 9, pp. 338343, 2011.

[2] F. Rosillo Calle, "Overview of biomass energy," in The biomass assessment handbook, pp. 23-48, Routledge, 2012.

[3] A. Yasar, S. Nazir, A. B. Tabinda, M. Nazar, R. Rasheed, and M. Afzaal, "Socio-economic, health and agriculture benefits of rural household biogas plants in energy-scarce developing countries: a case study from Pakistan," Renewable Energy, vol. 108, pp. 19-25, 2017.

[4] P. J. Burke and G. Dundas, "Female labor force participation and household dependence on biomass energy: evidence from national longitudinal data," World Development, vol. 67, pp. 424-437, 2015.

[5] R. Chandra, H. Takeuchi, and T. Hasegawa, "Methane production from lignocellulosic agricultural crop wastes: a review in context to second generation of biofuel production," Renewable and Sustainable Energy Reviews, vol. 16, no. 3, pp. 1462 1476, 2012.

[6] A. G. Mwakaje, "Dairy farming and biogas use in Rungwe district, South-west Tanzania: a study of opportunities and constraints," Renewable and Sustainable Energy Reviews, vol. 12, no. 8, pp. 2240-2252, 2008.

[7] T. Abbasi and S. A. Abbasi, "Biomass energy and the environmental impacts associated with its production and utilization," Renewable and Sustainable Energy Reviews, vol. 14, no. 3, pp. 919-937, 2010.

[8] T. L. Anderman, R. S. DeFries, S. A. Wood, R. Remans, R. Ahuja, and S. E. Ulla, "Biogas cook stoves for healthy and sustainable diets? A case study in Southern India," Frontiers in Nutrition, vol. 2, p. 28, 2015.

[9] K. C. Surendra, D. Takara, A. G. Hashimoto, and S. K. Khanal, "Biogas as a sustainable energy source for developing countries: opportunities and challenges," Renewable and Sustainable Energy Reviews, vol. 31, pp. 846-859, 2014.

[10] T. J. Decker, Modeling tool for household biogas burner flame port design, A, Colorado State University. Libraries, 2017.

[11] E. Orhorhoro, J. Oyejide, and S. Abubakar, "Design and construction of an improved biogas stove," Arid Zone Journal of Engineering, Technology and Environment, vol. 14, pp. 325-335, 2018.

[12] N. P. a. A. N. V. K. Sukhwani, "Design and performance evaluation of improved biogas stove (IBS) by preheating of biogas," International Journal of Scientific Engineering and Technology, vol. 6, pp. 70-74, 2017.

[13] V. Tumwesige, D. Fulford, and G. C. Davidson, "Biogas appliances in sub-Sahara Africa," Biomass and Bioenergy, vol. 70, pp. 40-50, 2014.

[14] S. W. Demissie, V. A. Ramayya, and D. T. Nega, "Design, fabrication and testing of biogas stove for 'Areke'distillation: the case of Arsi Negele, Ethiopia, targeting reduction of fuelwood dependence," International Journal of Engineering Research, vol. 5, 2016.

[15] D. Fulford, Biogas stove design, Kingdom Bioenergy, Ltd, Reading, UK, 1996.

[16] D. Fulford, Biogas stove design, Reading, UK, Kingdom Bioenergy, Ltd, 1996.

[17] FACT Foundation, Manual for the construction and operation of small and medium size biogas systems, Clube de Agricultores, 2012. 
[18] T. Stolarski, Y. Nakasone, and S. Yoshimoto, Engineering Analysis with ANSYS Software, Butterworth-Heinemann, 2018.

[19] W. P. Jones and B. E. Launder, "The prediction of laminarization with a two-equation model of turbulence," International Journal of Heat and Mass Transfer, vol. 15, no. 2, pp. 301314, 1972.

[20] B. E. Launder and D. B. Spalding, "The numerical computation of turbulent flows," in Numerical prediction of flow, heat transfer, turbulence and combustion, pp. 96-116, Elsevier, 1983.

[21] M. Noor, A. P. Wandel, and T. Yusaf, "Detail guide for CFD on the simulation of biogas combustion in bluff-body mild burner," in Proceedings of the 2nd International Conference of Mechanical Engineering Research (ICMER 2013), pp. 1-25, Bukit Gambang Resort City, Kuantan, Pahang, Malaysia, 2013.

[22] A. M. I. Yousef, Y. A. Eldrainy, W. M. el-Maghlany, and A. Attia, "Upgrading biogas by a low-temperature $\mathrm{CO}_{2}$ removal technique," Alexandria Engineering Journal, vol. 55, no. 2, pp. 1143-1150, 2016.

[23] V. M. Berrueta, R. D. Edwards, and O. R. Masera, "Energy performance of wood-burning cookstoves in Michoacan, Mexico," Renewable Energy, vol. 33, no. 5, pp. 859-870, 2008.

[24] D. R. Ahuja, V. Joshi, K. R. Smith, and C. Venkataraman, "Thermal performance and emission characteristics of unvented biomass-burning cookstoves: a proposed standard method for evaluation," Biomass, vol. 12, no. 4, pp. 247-270, 1987.

[25] P. Visser, "The testing of cookstoves: data of water-boiling tests as a basis to calculate fuel consumption," Energy for Sustainable Development, vol. 9, no. 1, pp. 16-24, 2005.

[26] P. R. Bailis, D. Ogle, N. Maccarty, D. S. I. From, K. R. Smith, and R. Edwards, The water boiling test (WBT), pp. 1-38, Clube de Agricultores, 2007.

[27] T. J. Decker, Modeling tool for household biogas burner flame port design, A, Masters Thesis, Colorado State University. Libraries, Fort Collins, Colorado, 2017.

[28] B. Mulugeta, S. W. Demissie, and D. T. Nega, "Design, optimization and CFD simulation of improved biogas burner for 'Injera'baking in Ethiopia," International Journal of Engineering Research \& Technology, vol. 6, pp. 1-7, 2017.

[29] D. D. Miller-Lionberg, A Fine-Resolution CFD Simulation Approach for Biomass Cook Stove Development, Colorado State University, 2011. 